\title{
Development of a Simple Method for the Determination of Toxicologically Relevant Species of Arsenic in Urine Using HG-AAS
}

\author{
Valery Bühl ${ }^{2}$, Cristina Álvarez ${ }^{1}$, Katarzyna Kordas ${ }^{3}$, Mariela Pistón ${ }^{2, *}$, Nelly Mañay ${ }^{1, *}$ \\ ${ }^{1}$ Center of Specialized Chemical Toxicology (CEQUIMTOX) Toxicology Area, Faculty of Chemistry, Universidad de la República, \\ Montevideo, Uruguay \\ ${ }^{2}$ Analytical Chemistry, Faculty of Chemistry, Universidad de la República, Montevideo, Uruguay \\ ${ }^{3}$ School of Social and Community Medicine, University of Bristol, Bristol, United Kingdom \\ *Corresponding author:mpiston@fq.edu.uy,nmanay@fq.edu.uy
}

Received June 27, 2015; Revised July 26, 2015; Accepted July 28, 2015

\begin{abstract}
Humans are exposed to arsenic (As) in the environment, in both organic and inorganic forms, and it has been widely demonstrated that the inorganic arsenic species (arsenate and arsenite) are the main toxic ones being drinking water one of the main sources of exposure worldwide. Urinary arsenic level is the recommended biomarker for assessing human exposure risks. Absorbed inorganic arsenic is metabolized to mono- and dimethylated arsenic compounds (MMA and DMA) prior to its excretion in urine. In this work, a simple procedure for the determination of toxicologically relevant arsenic species in urine (sum of As(III), As(V), MMA and DMA) using Hydride Generation Atomic Absorption Spectrometry (HG-AAS) was developed in order to obtain a feasible and selfsustainable technology for analysis and epidemiological studies when other expensive techniques are not available. Sample preparation was based on the derivation of arsenic species with L-cysteine. The limit of detection was $1.5 \mu \mathrm{g} \mathrm{L}^{-1}$, linearity up to $50 \mu \mathrm{g} \mathrm{L}-1$ and analytical precision was $12 \%$ (relative standard deviation, RSD \%, $\mathrm{n}=10$ ). Trueness was evaluated using spiked urine samples as well as a reference material. The range of acceptation for recoveries was established in $85-115 \%$ by means of a $t$-test at the $95 \%$ significance level. Recoveries for the four As species from spiked urine samples were in the range 87.8-113.5\%. The recovery from a reference material was $100.7 \%$. The comparison between the HG-AAS and high performance liquid chromatography-hydride generationcoupled to inductively coupled plasma mass spectrometry (HPLC-HG-ICPMS), considered as a gold standard technique, showed good agreement $\left(\mathrm{R}^{2}=0.94\right)$ for forty urine samples. The figures of merit were adequate for the determination of relevant species of As for biomonitoring purposes according to international regulations and it can be postulated as an alternative to more expensive techniques.
\end{abstract}

Keywords: arsenic, urine, toxicologically relevant species of arsenic, HG-AAS

Cite This Article: Valery Bühl, Cristina Álvarez, Katarzyna Kordas, Mariela Pistón, and Nelly Mañay, "Development of a Simple Method for the Determination of Toxicologically Relevant Species of Arsenic in Urine Using HG-AAS.” Journal of Environment Pollution and Human Health, vol. 3, no. 2 (2015): 46-51. doi: 10.12691/jephh-3-2-4.

\section{Introduction}

Arsenic has been considered as a typical example of a "poison" in human toxicology but it has been widely demonstrated that the inorganic arsenic species (arsenate and arsenite) are the main toxic ones, having shown to be carcinogens [1] while the organic natural species (arsenobetaine, arsencholine, arsenoribosides, etc.), present in seafood, are almost harmless to humans. Thus, the identification of specific arsenic species plays an important role in the interpretation of adverse effects and biological mechanisms of action in humans $[2,3,4]$.

Inorganic arsenic exposure through underground water has been responsible for the development of severe adverse effects on exposed populations in many regions worldwide, including several countries in Latin America. In South America, Argentina, Brazil and Chile are examples of world-famous naturally arsenic contaminated water, while in Uruguay this problem has not yet been evaluated systematically $[5,6,7,8,9]$. Then, it is necessary to develop systematic studies to assess population's chronic exposure to inorganic arsenic through drinking water and other sources, for regular biomonitoring of occupationally exposed workers.

Inorganic arsenic can be easily absorbed in the gastrointestinal tract at a rate between 40 and $100 \%$. Ingested inorganic arsenic is absorbed by the tissues and is metabolized to mono- and dimethylated arsenic compounds (MMA and DMA) prior to its excretion in urine. The harmful effects of inorganic arsenic may be affected by intra- and inter-individual differences in the processes of methylation $[4,10,11]$. 
Urinary arsenic level is the most common biomarker for assessing human exposure risks. There is a very clear need to properly quantify inorganic arsenic species in urine and its methylated metabolites, for the assessment and management of human environmental arsenic exposure in order to prevent and control the arsenicosis of exposed population, as well as for remediation and medical interventions [11]. This represents a major analytical challenge for developing countries because total urinary arsenic measurement, most commonly performed in these countries, assesses the combined exposure from all routes of exposure and all species of arsenic, including organic arsenic contribution from seafood consumption. Therefore, total urinary arsenic measurements may over-estimate arsenic exposure in populations with high seafood consumption $[12,13]$.

Occupational monitoring and research studies have focused on the sum of inorganic-related species (arsenate + arsenite + DMA + MMA) as a measure of inorganic arsenic exposure. Reference values for the sum of inorganic arsenic and its metabolites in urine recommended for occupationally exposed workers are less than $35 \mu \mathrm{g} \mathrm{L}^{-1}$ measured at end of a workweek [14]. For general population, conclusions from the National Health and Nutrition Examination Survey (NHANES) 2003-2004 data indicate that a urine sample of As $<20 \mu \mathrm{g} \mathrm{L}^{-1}$ is likely to have little contribution from organic arsenic species [15].

Atomic Spectrometry (AS) is the technique used to determine total arsenic at trace levels, and Atomic Fluorescence Spectrometry (AFS) or Atomic Emission Spectrometry coupled to a mass detector (ICPMS) $[16,17,18,19]$ are frequently used. The latter is very expensive, whereas AFS is not common in routine laboratories. For total As determination, Electrothermal Atomization Atomic Absorption Spectrometry (ET-AAS) is widely used [20]. For As speciation ICPMS coupled to HPLC is required, while for the determination of the species that generate hydrides (As(III), As(V), DMA and MMA) Hydride Generation Atomic Absorption Spectrometry (HG-AAS) can be used [19,21]. HG-AAS is preferable to ET-AAS because it provides separation of the analyte from the matrix, reducing the effects of several interferences [16,22]. For better detection limits, HG can be also coupled to HPLC-ICPMS [23]. This instrumentation is very expensive and it is not yet available for analysis in Uruguay.

The aim of this work was the development of a simple procedure for the determination of toxicologically relevant arsenic species in urine (sum of As(III), As(V), MMA and DMA) using HG-AAS, in order to obtain a feasible and self-sustainable technology for analysis and epidemiological studies, according to international recommendations and national regulations. This method can be postulated as an alternative to expensive gold standard techniques such as HPLC-ICPMS or HPLC-HG-ICPMS, since we demonstrate that the results are statistically comparable.

\section{Materials and Methods}

\subsection{Reagents}

All glassware was soaked overnight in $10 \%(\mathrm{v} / \mathrm{v})$ nitric acid $\left(\mathrm{HNO}_{3}\right)$ and then rinsed with purified water. Purified water was obtained from a Millipore Simplicity 185 (ASTM type I, 18.2 M $\Omega . c m$ resistivity). All reagents were of analytical-reagent grade or better.

Arsenic standards: As (V) $1000 \mathrm{mg} \mathrm{L}^{-1}$ (Fluka), Disodium methyl arsenate hexahydrate (MMA, > 97.5\%, Chem Service), As(III)-oxide (Sigma-Aldrich), cacodylic acid (DMA, >99\%, Sigma-Aldrich), L -Cysteine (>97\%, Sigma-Aldrich) and Sodium tetrahydroborate $\left(\mathrm{NaBH}_{4}\right.$, 99\%, Sigma-Aldrich).

The stock solutions of As(III), MMA, and DMA were prepared monthly and kept refrigerated at $4^{\circ} \mathrm{C}$. All arsenic (species) solutions were stable under these conditions when tested after 1 month.

The As(III) stock standard solution $1000 \mathrm{mg} \mathrm{L}^{-1}$ was prepared by dissolving an appropriate amount of As(III)oxide in $5 \mathrm{~mL}$ of sodium hydroxide $2 \mathrm{M}$, neutralized with $\mathrm{HCl} 2 \mathrm{M}$ and diluting with purified water.

DMA and MMA stock standard solutions $1000 \mathrm{mg} \mathrm{L}^{-1}$ were prepared by dissolving an appropriate amount in purified water.

An aliquot of those solutions was diluted with water to give the appropriate concentrations of working standard solutions.

Aqueous solutions of L-cysteine $6 \% \quad(\mathrm{w} / \mathrm{v})$ was prepared fresh daily. $\mathrm{NaBH}_{4} 1 \%(\mathrm{w} / \mathrm{v})$ in $0.5 \%(\mathrm{w} / \mathrm{v})$ sodium hydroxide solution was prepared prior to use.

The hydrochloric acid solution $(\mathrm{HCl}) \quad 0.1 \mathrm{M}$ was prepared by diluting appropriate volumes of concentrated hydrochloric acid (37.8\%, Fisher Scientific) in purified water.

\subsection{Instrumentation}

All measurements were carried out using a Varian SpectrAA 55B atomic absorption spectrometer, operated at $193.7 \mathrm{~nm}$, fitted with a 10 -cm burner (air-acetylene flame) and a T-shaped quartz absorption cell VGA 76/77 (Varian). The slit width was $0.5 \mathrm{~nm}$. A hollow cathode lamp (Varian) was used as light source as recommended by the manufacturer.

A flow system accessory VGA-77 was used for the hydride generation. The reductant agent was $\mathrm{NaBH}_{4}$ and the acid reagent was $\mathrm{HCl}$. Nitrogen was the carrier gas.

\subsection{Methods}

\subsubsection{Sample Preparation}

For the development and validation of the methodology, a pool of at least three urine samples from healthy occupationally non-exposed volunteer adults was used.

Sample preparation consisted of a derivation with Lcysteine of arsenic species. This method is based on the fact that $\mathrm{As}(\mathrm{III})+\mathrm{As}(\mathrm{V})$ and the methylated species (MMA + DMA) reacted with L-cysteine in acid medium, generating tioderivated compounds that originate arsines at similar velocities, which allows quantification of the total amount without overestimating or underestimating of other species. Thus sum of the four toxicologically relevant species is determined (As(III) + As(V) + MMA + DMA), being this sum essentially the 'hydride-reactive' fraction $[24,25,26,27,28]$. To determine the sum of the four species, hydride generation technique based on the reduction of them to arsine $\left(\mathrm{AsH}_{3}\right)$ with $\mathrm{NaBH}_{4}$ in acid medium $(\mathrm{HCl})$ was used. 
The concentrations of $\mathrm{NaBH}_{4}$ and $\mathrm{HCl}$ are critical parameters to optimize in HG-AAS. These variables affect the sensibility and precision of the method and they depend on the matrix.

\subsubsection{Analytical Procedure}

The analytical procedure presented bellow was validated according to Eurachem Guide for method validation [29].

Two intermediate standard solutions $\left(10 \mathrm{mg} \mathrm{L}^{-1}\right.$ and $0.05 \mathrm{mg} \mathrm{L}^{-1}$ ) were prepared daily by dilution of the $\mathrm{As}(\mathrm{V})$ $1000 \mathrm{mg} \mathrm{L}^{-1}$ stock solution with purified water. The As(V) calibration curve was prepared by accurately measuring $0.1,0.2,0.5$ and $1.0 \mathrm{~mL}$ of the intermediate standard solution of $\mathrm{As}(\mathrm{V})\left(0.05 \mathrm{mgL}^{-1}\right)$, followed by the addition of urine to a final volume of $10 \mathrm{~mL}$. The final $\mathrm{As}(\mathrm{V})$ concentrations were 5.0, 10.0, 25.0 and $50.0 \mu \mathrm{g} \mathrm{L}^{-1}$.

For the derivation step, $2.5 \mathrm{~mL}$ of L-cysteine $(6 \% \mathrm{w} / \mathrm{v})$ were added to $5 \mathrm{~mL}$ of the samples and standards (prepared with fresh urine as explained above). The mixture was stirred for 2 minutes to homogenize and then left to stand at room temperature for 30 minutes. Afterwards 2 drops of octanol were added to the solution in order to prevent foaming in the hydride generation device; the measurements were carried out using this solution. The obtained signal corresponds to total As (III) content in the sample (or standard) generated from the 'hydride-reactive' fraction (As(III) + As(V) + MMA + DMA).

When samples with As levels higher than $50 \mu \mathrm{g} \mathrm{L}^{-1}$ are analyzed, the aliquot of urine must be modified (less than $5 \mathrm{~mL}$ ) in order to obtain a concentration within the calibration range.

\subsubsection{Comparison of Analytical Techniques}

Using the validated methodology, the sum of As(III) + $\mathrm{As}(\mathrm{V})+\mathrm{MMA}+\mathrm{DMA}$ was determined in urine samples and the results were compared with those obtained with a well-reported technique as HPLC-HG-ICP-MS for As speciation (gold standard technique).

This comparative assay was performed in urine samples obtained in previous research studies on Uruguayan children. The aim of the source study was to examine the effects of low-level arsenic exposure on cognition of firstgrade children. The overall study methodology is available elsewhere [30].

First morning urine samples were collected in screwtop cups. To decrease potential contamination of the sample from the receptacle, each cup was rinsed repeatedly with $10 \% \mathrm{HNO}_{3}$ and deionized water before distribution to families for data collection.

For the aims of that study, urine samples were analyzed in Karolinska Institutet, Stockholm, Sweden where urinary arsenic species were measured by HPLC-HGICPMS (Agilent 7500cs, Agilent Technologies, Tokyo, Japan) [31,32].

Control remaining urine samples were kept frozen at $-20^{\circ} \mathrm{C}$ in $10 \mathrm{~mL}$ plastic tubes in the Center of Specialized Chemical Toxicology (CEQUIMTOX), Faculty of Chemistry, Montevideo, Uruguay, for further uses as children's parents had approved in their respective informed consent. The validated HG-AAS methodology was applied for the determination of the sum of
As(III)+As(V)+MMA+DMA in 40 of those archived urine samples and compared with the results obtained in the Laboratory from Sweden.

\section{Results and Discussion}

\subsection{Optimization of the Hydride Generation Conditions}

Optimal conditions for hydride generation were established. The evaluated parameters were concentration of the reductant agent $\left(\mathrm{NaBH}_{4}\right)$ in three levels $0.5,1.0$ and $1.5 \%(\mathrm{w} / \mathrm{v})$, and concentration of acid $(\mathrm{HCl})$ in five levels: $0.01,0.05,0.1,0.2$ and $0.5 \mathrm{M}$. These parameters were studied using a urine sample fortified with $20 \mu \mathrm{g} \mathrm{L}^{-1}$ of each of the four arsenical species tested.

Based on information published in the literature [27] the L-cysteine concentration was fixed in $6 \%(\mathrm{w} / \mathrm{v})$, since it was reported to be adequate for this application and the $\mathrm{NaBH}_{4}$ varied using a concentration of $2 \mathrm{M}$ for $\mathrm{HCl}$ as recommended by the manufacturer of the hydride generator device. Table 1 shows the results obtained for each species when the variable was $\mathrm{NaBH}_{4}$ concentration.

Table 1. Signal variation for each species with the concentration of $\mathrm{NaBH}_{4}$ using $\mathrm{HCl} 2 \mathrm{M}$ and L-cysteine $6 \%(\mathrm{w} / \mathrm{v})$. RSD: relative standard deviation $(n=5)$

\begin{tabular}{cccccc}
\hline & \multicolumn{4}{c}{ Absorbance/Concentration } & \\
\cline { 2 - 5 } $\mathrm{NaBH}_{4}(\% \mathrm{w} / \mathrm{v})$ & As(IIII) & As(V) & MMA & DMA & RSD (\%) \\
\hline 0.5 & 3236 & 3090 & 2118 & 2137 & 22.7 \\
1.0 & 5034 & 4660 & 4796 & 4692 & 3.5 \\
1.5 & 4170 & 4285 & 3952 & 3867 & 4.7 \\
\hline
\end{tabular}

The optimum condition was selected considering the better precision and the highest radio signal to concentration for the four species. Thus, the concentration for $\mathrm{NaBH}_{4}$ was fixed in $1 \%(\mathrm{w} / \mathrm{v})$ in $\mathrm{NaOH} 0.5 \%(\mathrm{w} / \mathrm{v})$.

Since it is reported that the concentration of $\mathrm{HCl}$ can be less than $2 \mathrm{M}$ for As determinations using HG-AAS, with the optimum $\mathrm{NaBH}_{4}$ concentration fixed the $\mathrm{HCl}$ concentration was varied [25,26,27,28]. This is important not only to optimize the experiment but also to be in good agreement with the Green Chemistry principles.

Five levels of diluted acid were tested evaluating the slopes of calibration of the four As species (analytical sensitivity). The curves were in the range of 1 to $50 \mu \mathrm{g} \mathrm{L}^{-1}$.

Table 2 shows the results obtained. The optimum concentration of $\mathrm{HCl}$ was $0.1 \mathrm{M}$ since the precision was the best and the analytical sensitive was adequate for the four species.

Table 2. Variation of the slopes of calibration for each species with the concentration of $\mathrm{HCl}$, using $\mathrm{NaBH}_{4} 1 \%(\mathrm{w} / \mathrm{v})$ and L-cysteine $6 \%$ $(w / v)$. RSD: relative standard deviation $(n=5)$

\begin{tabular}{cccccc}
\hline HCl $(\mathrm{M})$ & As(III) & As(V) & MMA & DMA & RSD (\%) \\
\hline 0.01 & 0.013 & 0.012 & 0.010 & 0.010 & 12.1 \\
0.05 & 0.012 & 0.010 & 0.011 & 0.009 & 12.4 \\
0.10 & 0.011 & 0.009 & 0.010 & 0.009 & 10.3 \\
0.20 & 0.011 & 0.008 & 0.010 & 0.008 & 12.9 \\
0.50 & 0.008 & 0.007 & 0.005 & 0.005 & 19.2 \\
\hline
\end{tabular}

The optimum flow rates were $6 \mathrm{~mL} \mathrm{~min}^{-1}$ for the sample, $1.8 \mathrm{~mL} \mathrm{~min}^{-1}$ for the $\mathrm{HCl}$ and $1.6 \mathrm{~mL} \mathrm{~min}^{-1}$ for the 
reductant agent $\left(\mathrm{NaBH}_{4}\right)$. These are the conditions recommended by the manufacturer and indicated in the manual.

\subsection{Validation}

Once the critical parameters where optimized, the main figures of merit were evaluated in order to validate the developed method.

To investigate the possible existence of multiplicative interferences the slope of the calibration curve in water was compared with that of the standard additions curve by means of statistical hypothesis testing [33]. It was found that the slopes were significantly different, suggesting the existence of such interferences.

For this reason, it was decided that the calibration curve would be made in urine (standard addition method). The urine used for calibration was from non-exposed adults, as explained above (urine pool).

For the evaluation of linearity, 6 urines fortified with $\mathrm{As}(\mathrm{V})$ in the range $0-50 \mu \mathrm{L} \mathrm{L}^{-1}$ were measured $(\mathrm{n}=5)$ and the results were plotted as a function of the concentration. Analytical curve was $\mathrm{A}=0.0109 \mathrm{C}+0.0087$ (A = absorbance, $\mathrm{C}=$ concentration in $\mu g \mathrm{~L}^{-1}, \mathrm{R}^{2}>0.99$ ). Linear range was established from the concentration corresponding to the quantification limit up to $50 \mu \mathrm{g} \mathrm{L}^{-1}$, confirmed by visual inspection of the plot and analysis of residuals.

Routine calibration curve was thus established in the range 5 - $50 \mu \mathrm{g} \mathrm{L}^{-1}$ using $\mathrm{As}(\mathrm{V})$, since there were no significate differences between the slopes for the other species (As(III), DMA and MMA) so the results can be expressed as $\mathrm{As}(\mathrm{V})$. In addition, the urine pool used for calibration (without As addition) must be measured as a blank. This range is adequate for screening analysis and control purposes since the regulation indicates that the sum of inorganic arsenic and its metabolites (MMA and DMA) in urine recommended for occupationally exposed workers should be less than $35 \mu \mathrm{g} \mathrm{L}^{-1}$.
Detection (LOD, 3 $\sigma$ ) and quantification (LOQ, 10 $\sigma$ ) limits were estimated by measuring the dispersion of a pool of urine samples from non-exposed voluntaries $(n=10)$ without As addition (blanks) signals and referring the measurements to the calibration curve. In these conditions, LOD was 1.5 and LOQ $5.1 \mu \mathrm{L} \mathrm{L}^{-1}$.

Precision (RSD \%) was estimated by both instrumental and analytical repetition. For analytical precision, 10 samples of spiked urine (pool) were analyzed. Each sample was measured 10 times (for instrumental precision). The analytical precision was $12 \%$ (expressed as RSD \%), for a concentration of $15 \mu \mathrm{g} \mathrm{L}^{-1}$.

Repeatability $(n=10)$ for the various levels of a calibration curve (5 -50 $\mu \mathrm{g} \mathrm{L}^{-1}$ ) was in the range $5.3 \%$ (for the highest concentration) to $8.1 \%$ (for the lowest one).

LOD, LOQ and precision were similar than those reported by Lindberg et al. using HPLC-HG-AFS expressed as $\mathrm{As}(\mathrm{V})$, in fact the limits are slightly lower [23]. Therefore, there is no need to use expensive technology to achieve detection limits that fit for the purpose.

Trueness was evaluated as recovery from the analysis of a reference material provided by the German External Quality Assessment Scheme (G-EQUAS) for proficiency testing and coded "Intercomparison programme 54:2014 for toxicological analysis in biological materials”, as well as from analysis of spiked samples [34].

The reference value for this sample was $29.3 \mu \mathrm{g} \mathrm{L}^{-1}$ (tolerance range: 21.2-37.4) and the obtained value using the proposed methodology was $29.5 \pm 3.5 \mu \mathrm{g} \mathrm{L}{ }^{-1}$ which represents a recovery of the $100.7 \%$.

Urine samples ( $n=10)$ were spiked with As(III), As(V), DMA and MMA individually in two concentration levels (20 and $30 \mu \mathrm{g} \mathrm{L}^{-1}$ ) and also spiked with the four species combined in each sample at the same concentration levels.

All the standards and samples were processed as described in section 2.3.2.

Table 3 shows the results obtained expressed as recovery percentage calculated as $100 \mathrm{x}$ [found / added].

Table 3. Recoveries obtained for spiked samples

\begin{tabular}{cccccc}
\hline Conc. $\left(\mu \mathrm{L} \mathrm{L}^{-1}\right)$ & As(III) & As(V) & MMA & DMA & As(III)+ As(V) + MMA + DMA \\
\hline 20.0 & 100.7 & 91.8 & 97.9 & 88.9 & 100.7 \\
30.0 & 87.8 & 103.0 & 100.4 & 113.5 & 91.8 \\
\hline
\end{tabular}

The obtained recoveries percentages must be between an interval that ensures no bias and no contamination, this range was estimated using a statistical test. This test is a tool to stablish an acceptable range of recoveries (the mean value is $100 \%$ ) considering the number of samples and the precision in these experimental conditions [29].

Recoveries were in the range $87.8-113.5 \%$. These values were compared with the nominal value of $100 \%$ by means of the Student's $t$-test, finding a $t$-value of 0.03 $(t(0.05,5)$ is 2.78$)$ [33], so it may be concluded that at the 95\% significance level recoveries do not differ significantly from $100 \%$, and the trueness of the method is ensured. The acceptable interval, considering the uncertainty, was stablished in the range $85-115 \%$. Recoveries higher than $100 \%$ are associated to the normal uncertainty of the methodology (also the gold standard technique has a normal uncertainty of $10 \%$ at these levels of concentration).
Since the blanks have no significant signals, there is no evidence of contamination and values within this range have no bias.

\subsection{Comparison of Analytical Techniques}

The proposed method was applied to analyze 40 samples as described in section 2.3.3 and the results compared with the gold standard technique HPLC-HGICPMS. The As levels informed correspond to the sum of As toxicologically relevant species in urine (As(III)+As(V)+MMA+DMA).

In Figure 1, shows the results obtained comparing the two techniques, and their correlation. Ideally, both methods are equal or equivalent when the equation for a linear tendency is $\mathbf{y}=\mathbf{1} \mathbf{x}($ slope $=1$, intercept $=0)$.

The graphic shows that the correlation was adequate, so both results were in good agreement, within the validated concentration range $\left(\mathrm{R}^{2}=0.9445\right)$, slope $=1.0694$ and 
intercept $=-0.6256$. The two methods appear to be particularly close at the lower range of exposure.

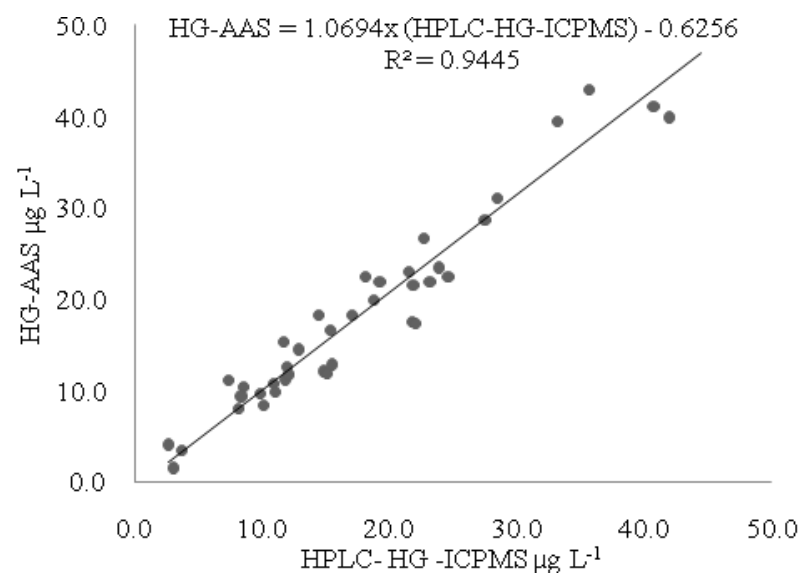

Figure 1. Comparison of the results obtained using HG-AAS vs HPLCHG-ICPMS in urine $(\mathrm{n}=40)$.

The obtained regression coefficient and equation are in accordance with those reported by Lindberg et al. [23] and in our case; the intercept is lower than the detection limit, which means a better agreement between the compared methods.

Considering the variability of the matrix, we can conclude that the developed method is comparable to the HPLC-HG-ICPMS and adequate for screening and biomonitoring, among other purposes.

This proposed method using HG-AAS resulted accurate for this biological matrix and has proven to be an alternative for more expensive techniques as HPLC-HGICPMS, used for arsenic speciation in urine.

\section{Conclusions}

A simple and fast methodology for the determination of relevant toxic species of arsenic in urine using HG-AAS technique was developed and validated.

This methodology can be used in several applications: a) as a first approach in the assessment of general population's chronic exposure and its health impacts, b) as an advisory service to the scientific and environmental health communities, c) for future research and for systematic population surveillance and d) for biomonitoring of exposed workers.

Based on the results of this study, protocols for analysis can be established using an economic analytical tool for the determination of inorganic arsenic biomarker.

These protocols are necessary for health prevention in arsenic occupationally exposed workers, for biomonitoring arsenic environmentally exposed general population and for clinical diagnosis, medical controls and risk assessment not only in Uruguay but also in other countries.

The developed method can be used to provide baseline arsenic urine levels for physicians and public health officials to determine whether people have been exposed to higher levels of arsenic than are found in the general population. This data can also help scientists to plan and conduct research on exposure and health effects in developing countries that do not have the gold standard techniques available.
In light of the current knowledge on the toxicity of arsenic species, the proposed method has significant advantages over the determination of total arsenic which included both inorganic and organic arsenic species and it is a very good alternative analytical option for the determination of relevant toxicological As species.

Therefore, this newly method has clear applications in Uruguay and other countries in the region, as well as other low-income countries.

\section{Acknowledgement}

The authors gratefully acknowledge the Agencia Nacional de Investigación e Innovación (Grant ANII; FMV_3_2013_1_100439), PEDECIBA - Química, UdelaR - Comisión Sectorial de Investigación Científica (CSIC) and National Institute of Health (NIH ES019949, PI: Kordas) for their financial support, and also Dr. Elena Queirolo and Mónica Daleiro from the Catholic University of Uruguay.

\section{References}

[1] Momoyo Sakuma, A, Mello De Capitani, E. and Tiglea, Pin, Metais: Gerenciamento da Toxicidade, Atheneu Intertox, San Pablo, Brazil, 2003.

[2] Akter, K.F., Owens, G., Davey, D.E. and Naidu, R., “Arsenic speciation and toxicity in biological systems", Reviews of Environmental Contamination and Toxicology, 184, 97-149, 2005.

[3] ATSDR, Arsenic Toxicological Profile, 2007. [Online] Available: http://www.atsdr.cdc.gov/toxprofiles/tp2.pdf [Accessed June 11, 2015].

[4] Mañay, N. Arsénico y Cadmio. In Toxicología ambiental y ocupacional. Rojas, M. M. (Ed.) Editorial Universidad de Rosario; Escuela de Medicina y Ciencias de la Salud, Bogotá, 2013, 257.

[5] WHO, Arsenic in drinking water, 2001. [Online] Available: http://www.who.int/water_sanitation_health/dwq/arsenic/en/ [Accessed June 11, 2015].

[6] Smedley, P. and Kinninburgh, D., Essentials of Medical Geology, Impacts of the Natural Environment on Public Health, edited by Sellinus, O., Alloway, B., Centeno, J., Finkelman, R., Fuge, R., Lindh, U. and Smedley, P., Elsevier Academic Press, Burlington, USA, 2005.

[7] Centeno, J.A., Tseng, C.H., Van der Voet, G.B. and Finkelman, R.B., "Global Impacts of Geogenic Arsenic: A Medical Geology Research Case", AMBIO: A Journal of the Human Environment, 36(1), 78-81, February 2007.

[8] Castro de Esparza, M.L., "Arsénico en el agua de bebida de América Latina y su efecto en la salud pública.”, International Congress Natural Arsenic in Groundwaters of Latin America, Mexico City, CEPIS/OPS, Hojas de divulgación técnica, (95), 1-8, Dec. 2004. [Online] Available: http://www.bvsde.ops-oms.org/bvsacd/cd51/arsenico-agua.pdf [Accessed June 11, 2015].

[9] Mañay, N., Pistón, M., Goso, C. “Arsenic environmental and health issues in Uruguay: A multidisciplinary approach. In: One Century of the Discovery of Arsenicosis in Latin America (19142014)” in International, 5th International Congress on Arsenic in the Environment (As 2014), CRC Press Taylor and Francis Group, 145-153.

[10] Tseng, C.H., “A review on environmental factors regulating arsenic methylation in humans", Toxicology and Applied Pharmacology, 235(3), 338-350, March 2009.

[11] Ng, J.C., "Environmental Contamination of Arsenic and its Toxicological Impact on Humans”, Environmental Chemistry, 2 (3), 146-160, 2005.

[12] Kales, S.N., Huyck, K.L. and Goldman, R.H., "Elevated urine arsenic: Un-speciated results lead to unnecessary concern and further evaluations”, Journal of Analytical Toxicology, 30 (2), 8085, March 2006. 
[13] ATSDR, Agency for toxic substances and disease registry, Case Studies in Environmental Medicine. [Online] Available: http://www.atsdr.cdc.gov/csem/arsenic/docs/arsenic.pdf. [Accessed June 11, 2015].

[14] ACGIH, TLVs and BEIs, Signature Publications, Cincinnati, USA, 2010.

[15] CDC, Fourth National Report on Human Exposure to Environmental Chemicals, Centers for Disease Control and Prevention, 2009. [Online] Available: http://www.cdc.gov/exposurereport/pdf/FourthReport.pdf [Accessed June 11, 2015].

[16] Welz, B. and Sperling, M., Atomic Absorption Spectrometry, Willey-VCH, Weinheim, 1999.

[17] Zheng, J., Kosmus, W., Pichler-Semmelrock, F. and Köck, M., "Arsenic speciation in human urine reference materials using high-performance liquid chromatography with inductively coupled plasma mass spectrometric detection”, Journal of Trace Elements in Medicine and Biology, 13(3), 150-156, 1999.

[18] Brima, E.I., Haris, P.I., Jenkins, R.O., Polya, D.A., Gault, A.G. and Harrington, C.F., "Understanding arsenic metabolism through a comparative study of arsenic levels in the urine, hair and fingernails of healthy volunteers from three unexposed ethnic groups in the United Kingdom", Toxicology and Applied Pharmacology , 216 (1), 122-130, June 2006.

[19] Rivera-Núñez, Z., Meliker, J.R., Linder, A.M. and Nriagu, J.O. "Reliability of spot urine samples in assessing arsenic exposure", International Journal of Hygiene and Environmental Health, 213 (4), 259-264, July 2010.

[20] Michon, J. , Deluchat, V., Al Shukry, R., Dagot, C. and Bollinger, J.C., "Optimization of a GFAAS method for determination of total inorganic arsenic in drinking water”, Talanta 71(1), 479-485, January 2007.

[21] Dedina, J. and Tsalev, D.L., Hydride Generation Atomic Absorption Spectrometry, Willey, Chichester, 1995.

[22] Pistón, M., Silva, J., Perez-Zambra, R., Dol, I. and Knochen, M. "Automated method for the determination of total arsenic and selenium in natural and drinking water by HG-AAS", Environmental Geochemistry and Health, 34(2), 273-278, April 2012.

[23] Lindberg, A., Goessler, W., Grandér, M., Nermell, B., Vahter, M. "Evaluation of the three most commonly used analytical methods for determination of inorganic arsenic and its metabolites in urine", Toxicology Letters, 168, 310-318, November 2006.

[24] Rivera-Núnez, Z., Meliker, J. R., Linder, A. M., Nriagua, J. O. "Reliability of spot urine samples in assessing arsenic exposure",
International Journal of Hygiene and Environmental Health, 213 259-264, March 2010.

[25] Guo, T., Maasner, J., Tsalev. D. "Fast automated determination of toxicologically relevant arsenic in urine by flow injection-hydride generation atomic absorption spectrometry", Analytica Chimica Acta, 349 (1-3), 313-318, August 1997.

[26] Le, X.C., Cullen, W., Reimer, K. "Effect of cysteine on the speciation of arsenic by using hydride generation atomic absorption spectrometry”, Analytica Chimica Acta, 285 (3), 277285, January 1994.

[27] Carrero, P., Malavé, A., Burguera, J., Burguera, M., Rondón, C., "Determination of various arsenic species by flow injection hydride generation atomic absorption spectrometry: Investigation of the effects of the acid concentration of different reaction media on the generation of arsines”, Analytica Chimica Acta, 438 (1-2), 195-204, July 2001.

[28] Navoni, J.A., Olivera, N. M., Villaamil, E. C., “Cuantificación de arsénico por inyección en flujo-generación de hidrurosespectrometría de absorción atómica (IF-GH-EAA) previa derivatización con L-cisteína. Validación y comparación intermetodológica utilizando dos técnicas de referencia”, Acta Toxicológica Argentina 18(2), 48-54, December 2009.

[29] Magnusson, B., Örnemark, U. (eds.) "Eurachem Guide: The Fitness for Purpose of Analytical Methods - A Laboratory Guide to Method Validation and Related Topics”, (2nd ed.) [Online] Available: http://www.eurachem.org [Accessed June 24, 2015].

[30] Aditi, R., Queirolo, E., Peregalli F., Mañay, N., Martínez, G., Kordas, K. "Association of blood lead levels with urinary F2-8a isoprostane and 8-hydroxy-2-deoxy-guanosine concentrations in first-grade Uruguayan children”, Environmental Resarch 140, 127-135, July 2015.

[31] Gardner, R., J. Hamadani, M. Grandér, F. Tofail, B. Nermell, B. Palm, M. Kippler and M. Vahter, "Persistent exposure to arsenic via drinking water in rural Bangladesh despite major mitigation efforts." Am J Public Health, 101(l), 333-338, December 2011.

[32] Li, L., E. C. Ekstrom, W. Goessler, B. Lonnerdal, B. Nermell, M. Yunus, A. Rahman, S. El Arifeen, L. A. Persson and M. Vahter,"Nutritional status has marginal influence on the metabolism of inorganic arsenic in pregnant Bangladeshi women." Environ Health Perspect 116(3), 315-321, March 2008.

[33] Miller, J. N. \& Miller, J.C. (1993). "Estadística para Química Analítica”. (2nd ed.), Addison-Wesley Iberoamerican S.A. Wilmington, 1993.

[34] The German External Quality Assessment Scheme (G-EQUAS). For Analyses in Biological Materials [Online] Available: http://www.g-equas.de/info.htm [Accessed June 24, 2015]. 